\title{
ANÁLISE DE ICONICIDADE DAS VARIANTES DO TERMO CORONAVÍRUS EM LÍNGUA BRASILEIRA DE SINAIS - LIBRAS
}

\author{
ICONICITY ANALYSIS OF THE VARIANTS OF THE TERM \\ CORONAVIRUS IN BRAZILIAN SIGN LANGUAGE - LIBRAS
}

\author{
Higor Pereira de Brito ${ }^{1}$ \\ Renne Imar de Melo Souza ${ }^{2}$ \\ Walber Gonçalves de Abreu ${ }^{3}$ \\ Universidade Federal Rural da Amazônia (UFRA)
}

\section{RESUMO}

Atualmente, por conta dos avanços da COVID-19 pelo mundo surgiu a necessidade de as pessoas consumirem mais informações e se comunicarem de maneira remota. Além disso, houve a necessidade da criação de um léxico técnico pelos sinalizantes de línguas de sinais para suprir as necessidades de comunicação nesse novo cenário. Dessa forma, o presente artigo visa analisar a formação icônica dos sinais referentes ao termo "coronavírus" na Língua Brasileira de Sinais (Libras), nos níveis fonológico e morfológico, através de análises dos aspectos estruturais dos sinais e da descrição desse léxico sob a luz do modelo proposto por Taub (2004). A presente pesquisa se situa no nível exploratório e se caracteriza como do tipo: pesquisa básica. Foram selecionados 3 vídeos de redes sociais que apresentavam, cada um, uma variante do sinal de CORONAVÍRUS, essas variantes foram analisadas qualitativamente. Como resultados, temos que (i) o processo de criação desses sinais revela motivações relacionadas a origem da doença, a estrutura do vírus e ao contágio e sintomas da doença e; (ii) a estrutura fonológica das variantes revela o importante papel da configuração de mão e do movimento na constituição dos sinais. Com isso, concluímos que em léxicos emergentes a iconicidade tem um papel fundamental na constituição dos termos, esse fator não rebaixa as línguas de sinais ao status de línguas não naturais, mas sim, demonstra uma peculiaridade dessas línguas, que é a iconicidade. Mostrando assim, a riqueza das línguas de modalidade visual-gestual.

PALAVRAS-CHAVE: Léxico. Iconicidade. Língua Brasileira de Sinais. Coronavírus.

\begin{abstract}
Currently, since the COVID-19 comes up around the world, the people need more information and communicate remotely. In addition, it was created a technical léxicon for signers in sign languages in this new scenario. Thus, this article aims to analyze the iconic formation of signs referring to term "coronavirus" in Brazilian Sign Language (Libras), at the phonological and morphological levels, through analysis of the structural aspects of the signs and the description of this lexicon according to model proposed by Taub (2004). As a methodology, we adopted the exploratory level and it is characterized as a basic research type. We selected 3 videos from social networks that each presented a variant of the coronavirus signal, these variants were analyzed qualitatively. As results, (i) the process of creating these signs reveals motivations related to the origin of the disease, the structure of the virus and the contagion and symptoms of the disease and; (ii) the phonological structure of the variants reveals the important role of hand shape and movement in the constitution of signs. Therefore, we conclude that in emerging lexicons, the

\footnotetext{
${ }^{1}$ Graduando do Curso de Letras Libras da UFRA. E-mail higorpereira40@gmail.com

${ }^{2}$ Graduanda do Curso de Letras Libras da UFRA. E-mail: rennerimar@gmail.com

${ }^{3}$ Doutorando e Mestre em Letras - Estudos Linguísticos pela UFPA. Professor assistente da UFRA.

E-mail:walber.abreu@ufra.edu.br
} 
iconicity has a fundamental role in the constitution of terms, this factor does not lower sign languages to the status of non-natural languages, but rather demonstrates a peculiarity of these languages, the iconicity. And, it shows the richness of visual-gestural languages.

KEY-WORDS: Lexicon. Iconicity. Brazilian Sign Language. Coronavirus.

\section{INTRODUÇÃO}

Em 2020, diversos setores da sociedade necessitaram se isolar socialmente para conter a propagação da Sars-CoV-2, conhecida como o novo coronavírus ou simplesmente como coronavírus, causador da doença COVID-19. Esse fato mobilizou as lideranças políticas, sanitárias e de saúde. Além disso, outros setores científicos da sociedade também se mobilizaram para refletir o atual cenário mundial, como os linguistas que começaram a discutir questões de linguagem relacionadas ao coronavírus.

Dessa maneira, por conta dos avanços da COVID-19 pelo mundo todo, a população passou a consumir mais informações e a se comunicar com maior frequência entre si, especialmente, de forma remota. Além disso, houve a necessidade de criação de um léxico técnico e popular pelos falantes e sinalizantes de Línguas Orais (LO) e Línguas de Sinais (LS), respectivamente. Dessa maneira, observamos um surgimento rápido e repentino de discussões acerca do sinal a ser adotado para designar o coronavírus, isso fez com que algumas variantes para esse termo fossem criadas e reverberam até o momento.

Dessa forma, o presente artigo visa analisar a formação icônica dos sinais referentes ao termo coronavírus nos níveis fonológico e morfológico, através de análises dos aspectos estruturais dos sinais e da descrição desse léxico sob a luz do modelo proposto por Taub (2004).

Nesse sentido, explorar a iconicidade de sinais na Libras no nível fono-morfológico, utilizando variantes para um mesmo significante, pode contribuir consideravelmente para os avanços nos estudos linguísticos, no que diz respeito a criação de léxicos emergentes nas LS e a relação desse processo em línguas visual-gestual com as línguas orais-auditivas, assim, com os estudos da linguagem de um modo geral.

Para isso, elencamos as seguintes perguntas para nortear o trabalho:

(i) Como se deu o processo de criação desses signos linguísticos e as possíveis transformações ocorridas nesses sinais?

(ii) Qual a estrutura fonológica e morfológica das variantes de coronavírus?

(iii) Qual o papel da iconicidade na formação de léxicos emergentes?

Para isso, no primeiro momento tratamos sobre o léxico das LS e das discussões acerca do papel da iconicidade nos sinais. Após, tratamos da metodologia utilizada no trabalho seguida dos resultados e discussões da pesquisa. Por fim, tecemos nossas considerações finais.

\section{0 léxico das Línguas de Sinais}

Para Antunes (2012, p. 27) “o léxico [é] o amplo repertório de palavras de uma língua ou o conjunto de itens à disposição dos falantes para atender às suas necessidades de comunicação". Dessa maneira, ao falar ou sinalizar dispomos de um amplo repertório de escolhas a serem aplicadas de acordo com os contextos de uso da língua.

Em uma visão mais cognitiva sobre o léxico, Antunes (2012) afirma que,

a linguagem intermedeia nossa relação com o mundo. [...] Essa relação se dá entre as categorias cognitivas que construímos das coisas ao longo de nossa experiência e as palavras de que a língua vai dispondo para expressar tais categorias. Quer dizer, as palavras são 'a representação linguística' dessas categorias cognitivas que construímos e armazenamos [...]. O léxico corresponde, assim, ao inventário dos itens linguísticos com que expressamos essas categorias e subcategorias cognitivas. (p. 28). 
Dessa maneira, os itens lexicais de uma língua estão em constante renovação, uma vez que a sociedade muda e com ela, conceitos e concepções novas vão surgindo ou se reinventando, causando transformações no léxico. Sendo assim, podemos pontuar três processos básicos no léxico de uma língua: (i) lexicalização, quando novos itens são incorporados a língua; (ii) deslexicalização é o momento em que um item lexical entra em desuso; e (iii) atribuição de novos sentidos à itens já existentes (ANTUNES, 2012).

Nas LS, Brentari e Padden (2001) discutem sobre a constituição do léxico da Língua de Sinais Americana (ASL). No Brasil, Quadros e Karnopp (2004) trazem os autores supracitadas para pensar sobre a constituição do léxico da Libras.

De modo geral, em ambos os modelos de análise, os autores entendem que o léxico das línguas sinalizadas é constituído pelo léxico nativo e pelo léxico não nativo. Sendo o primeiro formado principalmente pelos classificadores, que são estruturas bastante peculiares às LS e o segundo composto pelos empréstimos linguísticos das LO, por exemplo, o Português, como demonstrado na figura (1) abaixo:

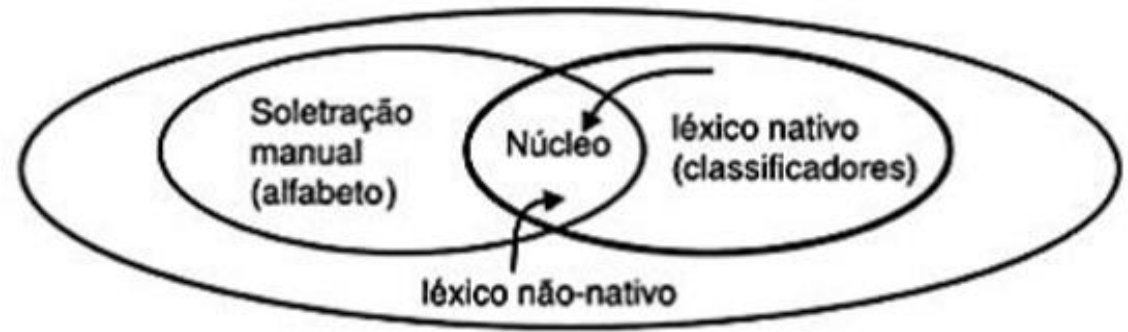

Figura 1: Proposta de constituição do léxico da Libras Fonte: Quadros e Karnopp, 2004 (p. 88)

Brentaria e Padden (2002) e Quadros e Karnopp (2004) afirmam que ambos os léxicos, nativo e não-nativo, podem estar no núcleo ou na periferia do léxico, uma vez que o núcleo comporta os sinais bem formados - aqueles que apresentam, pelo menos, apenas uma configuração de mão e duas orientações da palma da mão - enquanto que, os sinais que não obedecem às restrições fonológicas, se localizam na periferia do léxico. Esses, com o tempo, podem passar por mudança fonológicas e caminharem em direção ao núcleo (figura 2)

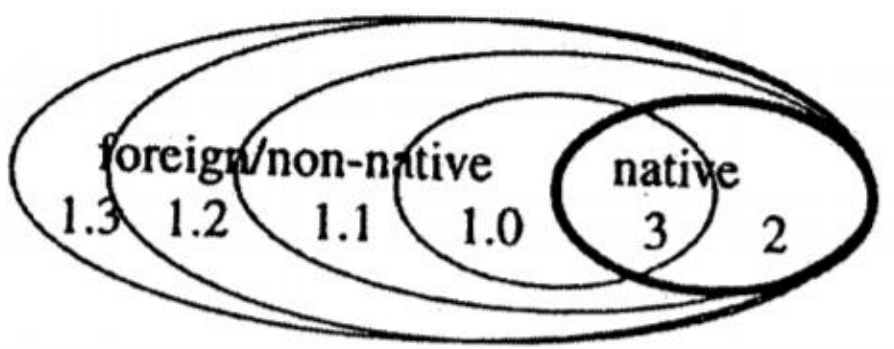

Figura 2: Proposta de constituição do léxico da ASL Fonte: Brentari e Padden, 2002 (p. 89)

Isto posto, discutiremos na próxima seção alguns aspectos sobre a iconicidade nas línguas sinalizadas e o seu papel na formação dos sinais.

\section{A iconicidade linguística como objeto de estudo nas Línguas de Sinais}

No início das investigações linguísticas das LS, a iconicidade era um fenômeno pouco explorado. Sob a ótica do estruturalismo, do behaviorismo e do formalismo era compreendida 
como uma característica negativa que aproximava as línguas de modalidade viso-espaciais às pantomimas e gestos.

Dessa forma, até meados da década de 80 , a arbitrariedade - considerada a principal e essencial característica das línguas humanas - assumiu o centro das atenções das pesquisas, impedindo os avanços na exploração das riquezas linguísticas específicas das LS (NAVES; MINEIRO; MORGADO, 2019).

O fenômeno da iconicidade consiste em uma representação similar ao referente, ao seu significado ou ambos, através de uma forma linguística. Atualmente, entendemos que a iconicidade é um fenômeno presente em todas as línguas, sejam elas orais ou sinalizadas, permeando todos os seus níveis linguísticos.

No entanto, por conta de as LS serem representadas visualmente, a relação forma e referente é mais evidente do que nas LO. Por conta disso, é comum que pessoas que desconhecem tais propriedades, facilmente associem as LS à mimicas e à gestos de significados rasos, de maneira preconceituosa (QUADROS, 2019; TAUB, 2004).

Uma das referências em estudos de iconicidade nas LS é a pesquisadora Sarah Taub (2003; 2004). A estudiosa investiga a iconicidade linguística e metáforas das LS, compreendendo tais fenômenos como fruto da relação entre a imagem mental - que os sinalizantes têm de determinado referente - e o seu significado. Em suas pesquisas, a autora nos apresenta diversas formas que a iconicidade está presente e se configura nessas línguas (mais especificamente na ASL), para isso, criou um modelo de esquematização para ilustrar como ocorre o processo de criação lexical.

O referido modelo objetiva oferecer ferramentas para a análise, descrição e explicação de itens icônicos de diversas línguas, de ambas as modalidades. Através dele é possível entendermos a complexidade de construção desse tipo de item linguístico, que envolve uma ampla observação dos objetos e conceitos (referentes), a captação somatossensorial de diversas informações deste referente e a criação (tradução) de imagens mentais a partir da cognição e interpretação destas informações.

Taub (2004) divide esse processo em 3 (três) etapas, conforme se vê na figura (3):

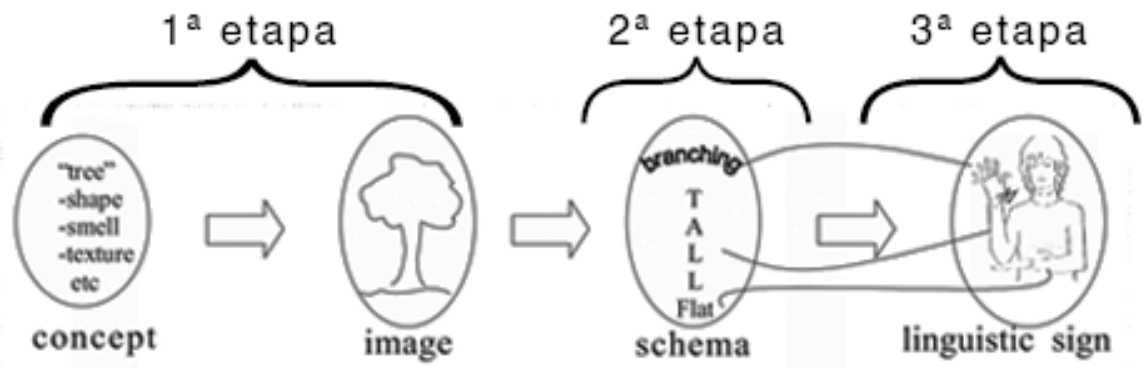

Figura 3: Esquema do processo de construção sinal ÁRVORE em ASL Fonte: Taub, 2004 (adaptado)

A primeira etapa consiste na seleção da imagem mental que está diretamente associada ao conceito original do seu referente. No exemplo ilustrado é possível perceber que essa construção resgata não somente uma imagem visual do objeto tree (árvore, em português), mas também o relaciona com outras características que o compõe, como por exemplo a sua textura (texture) e seu aroma (smell).

Após essa seleção, parte-se para a segunda etapa, onde ocorrerá a esquematização dessa imagem mental. Nesse processo os aspectos essenciais para a identificação do referente são mantidos e os desnecessários são excluídos. No exemplo apresentado por Taub (2004), para a imagem mental de árvore (tree) são mantidos: copa da árvore (branching), tronco (tall) e chão (flat). 
$\mathrm{Na}$ terceira e última etapa é realizada a codificação do esquema (schema), traduzindo-o para a língua por meio dos recursos linguísticos apropriados e disponíveis, resultando, assim, em um signo linguístico - sinal TREE, conforme a figura 3.

\section{Metodologia}

O presente estudo se localiza no nível exploratório e se caracteriza como do tipo: pesquisa básica, pois a sua finalidade é contribuir para a construção de novos conhecimentos - sem aplicação prática - e explorar conceitos e ideias visando proporcionar mais esclarecimentos acerca do fenômeno da iconicidade na Libras (GIL, 2008.).

Nesse sentido, adotou-se a abordagem qualitativa, por permitir o aprofundamento na realidade do objeto de pesquisa e, por consequência, permitir melhores compreensões, descrições e explicações a seu respeito. (GERHART; SILVEIRA, 2009.).

Para tanto, se fez necessária a realização de um levantamento de amostras como procedimento técnico para a coleta de dados (GIL, 2008.), objetivando identificar os sinais utilizados para sinalizar 'coronavírus' ou 'COVID-19', em Libras, a nível nacional. Contudo, verificamos que para ambos os termos se utiliza apenas um sinal e o contexto faz a distinção de significado entre o vírus e a doença.

Foram coletados dados da internet, mais especificamente vídeos em Libras de sites e de redes sociais acerca da temática em questão utilizando o cruzamento dos termos 'coronavírus $\mathrm{X}$ Libras' e 'COVID-19 X Libras'. A escolha das redes sociais como lócus de coleta de dados ocorreu tendo em vista que, devido a necessidade do isolamento social, na visão dos pesquisadores, essas redes representaram importante meio de comunicação e propagação de informações e orientações de cuidado e prevenção do vírus.

Dessa forma, foram selecionados três vídeos ${ }^{4}$, nos quais, cada um demonstra uma das variantes utilizadas para coronavírus no Brasil. O primeiro vídeo é o da variante 1 , retirado do site da TV INES, um portal que divulga informações e conhecimento e promove entretenimento com temáticas relacionadas à cultura surda e à cultura ouvinte. Os vídeos são sinalizados em Libras e contém legenda e locução. Essa webTV é uma criação do Instituo Nacional de Educação de Surdos (INES) e da Associação de Comunicação Educativa Roquette Pinto (ACERP).

O segundo vídeo, com a variante 2 , foi coletado da página do facebook 'dimar show de humor'. No vídeo, o ator traz uma reflexão sobre as variantes usadas para coronavírus. Ele fala do uso inicial da variante 1, seguida do uso da variante 2, validada pelos orientais e usada, inclusive, no gestuno e por fim, apresenta a variante 3 , criada pelos brasileiros.

O terceiro vídeo foi retirado da rede social instagram, do professor surdo Fabio de Sá @ fabio.ssilva. No vídeo, o professor explica que a comunidade surda de São Paulo juntamente com surdos de outras regiões se reuniu por meio de um grupo em rede social e criou um sinal para sinalizar coronavírus.

Os dados coletados passaram por análises embasadas na metodologia proposta por Taub (2003; 2004.) que descreve e explica a iconicidade e as metáforas presentes nas LS através de uma esquematização dividida em três etapas. A isso, foi relacionada à análise estrutural de aspectos fonológicos e morfológicos da Libras.

\section{Resultados e discussões}

Durante a coleta de dados, identificamos três variantes para o termo 'coronavírus' em Libras. A primeira variante foi o sinal utilizado nas primeiras semanas do aparecimento do vírus

\footnotetext{
${ }^{4}$ Vídeo 1: http://tvines.org.br/?p=20475

Vídeo 2: encurtador.com.br/egDIY

Video 3: https://www.instagram.com/p/B79qGr_pRIUv1NdVBqYjDJMiEM89fmt_EK2CJc0/
} 
pelo mundo. Em seguida, outras variantes surgiram a partir de novas discussões e reflexões sobre o termo, a segunda variante é um empréstimo linguístico de um sinal criado pelos surdos orientais e a terceira é um sinal criado pelos surdos brasileiros para se referir ao coronavírus.

É importante ressaltar que, assim como nas demais línguas, a confusão entre os termos referentes à família de vírus coronavírus e à doença COVID-19 se mostrou na Libras e, dessa forma, ainda hoje os sinalizantes de Libras usam um mesmo sinal para designar tanto o vírus quanto a doença. Entretanto, com as atualizações feitas pela ciência, os sinalizantes demarcam linguisticamente quando se referem ao vírus e quando se referem à doença.

Dessa forma, demonstramos abaixo nossas análises sobre cada uma das variantes encontradas:

(i) Variante 1

Com as primeiras informações recebidas dos cientistas, os surdos iniciaram discussões para denominar por meio de um sinal o novo vírus que surgia no mundo todo. Informações como a de que o vírus foi transmitido pela carne de um morcego a um humano, a rápida disseminação pelo corpo humano e o alto grau de contágio influenciaram a constituição da primeira variante, como podemos observar na figura 4. Contudo, percebemos que os surdos usaram com pouquíssima frequência a variante 1 , uma vez que os cientistas não deram certeza se o coronavírus veio realmente de um morcego

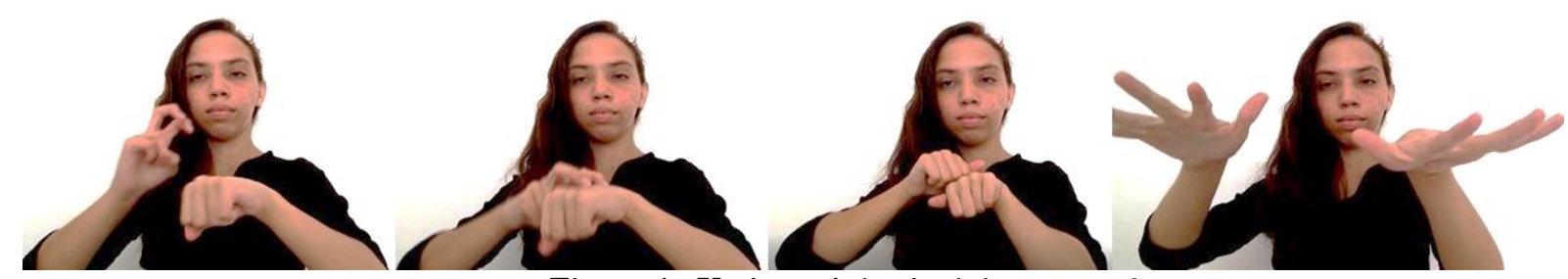

Figura 4 - Variante 1 do sinal de coronavírus

Fonte: elaborado pelos autores, 2021.

Analisando a variante 1 no modelo de Taub (2004), entendemos que são elencados os conceitos relacionados à forma, contágio rápido, sintomas e ao animal responsável pela transmissão da doença, o morcego. Desses conceitos, no momento da esquematização são selecionados os itens referentes a contaminação do organismo pelo morcego e proliferação do vírus e assim, codificados na estrutura do sinal, como demonstrado na figura 5.

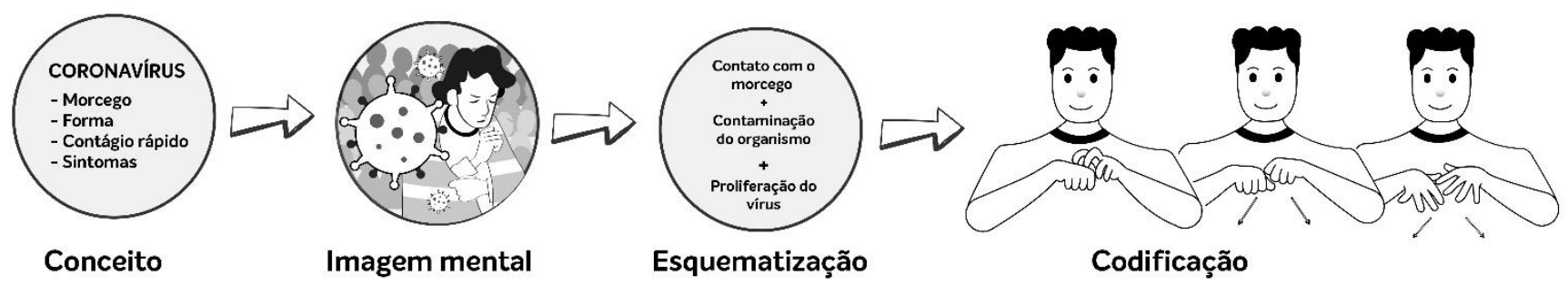

Figura 5 - Variante 1 no modelo de Taub, 2004.

Fonte: elaborado pelos autores, 2021.

Dessa forma, em relação a estrutura do sinal, analisamos que o contexto influencia a criação do léxico e, consequentemente, isso gera uma motivação mais clara na Libras. Dessa forma, propomos uma relação de estrutura e motivação nos sinais. Na primeira variante, visualizamos três momentos de articulação do sinal. Cada momento está descrito com suas respectivas motivações no quadro 1. 


\begin{tabular}{|c|c|c|c|}
\hline Momentos & Situação & Sinal & Motivação \\
\hline $\begin{array}{c}1^{\mathrm{o}} \\
\text { momento }\end{array}$ & $\begin{array}{l}\text { Contato do } \\
\text { morcego com o } \\
\text { sistema } \\
\text { fisiológico do } \\
\text { ser humano }\end{array}$ & & $\begin{array}{l}\text { - A Configuração da mão } \\
\text { dominante em remete ao } \\
\text { classificador atribuído à } \\
\text { animais em Libras, nesse caso, } \\
\text { ao morcego. Uma vez que, a } \\
\text { configuração de mão desse } \\
\text { primeiro momento da variante } \\
1 \text { é a mesma configuração } \\
\text { utilizada no sinal de } \\
\text { MORCEGO em Libras. O } \\
\text { movimento refere-se ao } \\
\text { contato do mamífero com o } \\
\text { corpo humano. }\end{array}$ \\
\hline $\begin{array}{c}2^{\circ} \\
\text { momento }\end{array}$ & $\begin{array}{l}\text { Contaminação } \\
\text { do organismo } \\
\text { com o vírus }\end{array}$ & & $\begin{array}{l}\text { - O movimento dos dedos de } \\
\text { ambas as mãos remete ao } \\
\text { espalhamento do vírus pelo } \\
\text { organismo do ser humano. }\end{array}$ \\
\hline $\begin{array}{c}3^{\circ} \\
\text { momento }\end{array}$ & $\begin{array}{c}\text { Espalhamento } \\
\text { do vírus }\end{array}$ & & $\begin{array}{l}\text { - O movimento de abertura das } \\
\text { mãos seguida de um } \\
\text { movimento direcional para } \\
\text { frente, refere-se } \\
\text { espalhamento do vírus na } \\
\text { sociedade } \\
\text { consequentemente, da doença } \\
\text { para as várias direções. }\end{array}$ \\
\hline
\end{tabular}

Quadro 1 - Motivações da variante 1 do sinal de coronavírus

(ii) Variante 2

Fonte: elaborado pelos autores, 2021.

Com novas informações divulgadas pela ciência, os surdos orientais decidiram criar um sinal para designar o coronavírus (figura 6). Com a criação de vídeos pelos surdos para disseminar esse novo sinal, as comunidades surdas de diversos países do mundo incorporaram a variante ao seu léxico. A rápida disseminação da nova variante por todo o mundo, revela o mundo globalizado e informacional que vivemos na atualidade, o qual os surdos estão totalmente imersos nele.

No Brasil, a variante 2 também foi incorporada ao léxico da Libras e passou a ser utilizada pelos surdos de diversos estados. Até o presente, alguns surdos, com menor frequência, ainda utilizam essa variante. 


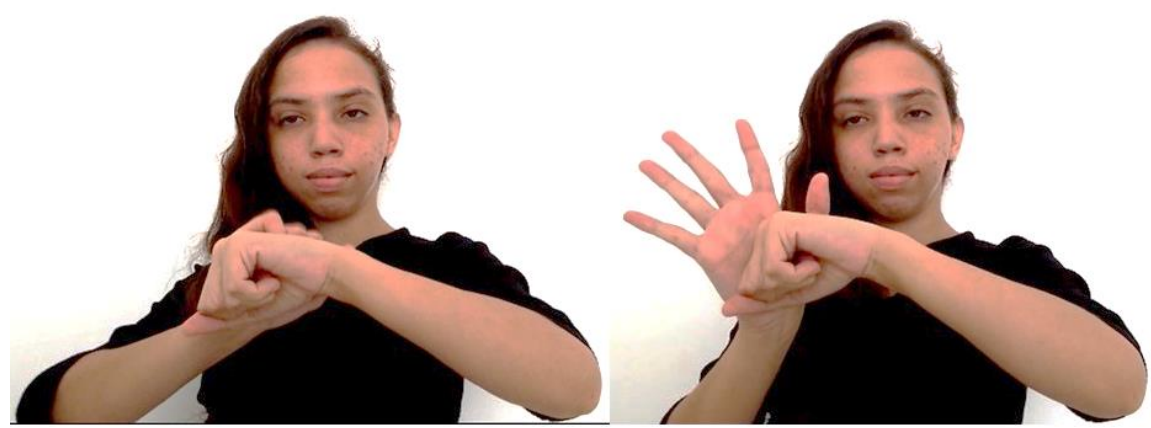

Figura 6 - Variante 2 do sinal de coronavírus

Fonte: elaborado pelos autores, 2021.

Em relação a análise da iconicidade presente na constituição desse sinal, identificamos que conceitos como formato, envelope, espícula e contágio rápido estão relacionados à constituição dessa variante. Desses, compõem a esquematização do sinal a estrutura do vírus, mais especificamente o envelope e as espículas (figura 10).

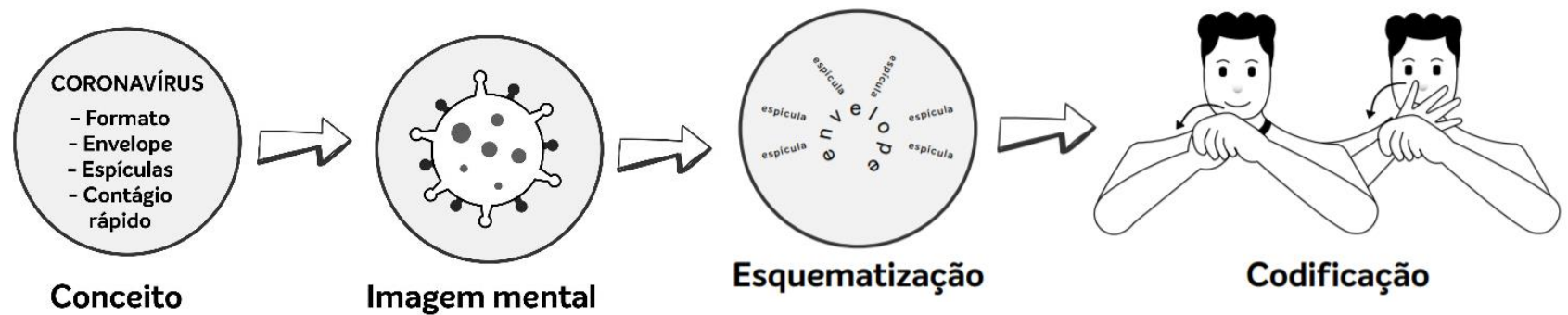

Figura 7 - Variante 2 no modelo de Taub, 2004. Fonte: elaborado pelos autores, 2021.

A estrutura fonológica da variante 2 revela dois momentos na articulação do sinal, como descrito no quadro 2.

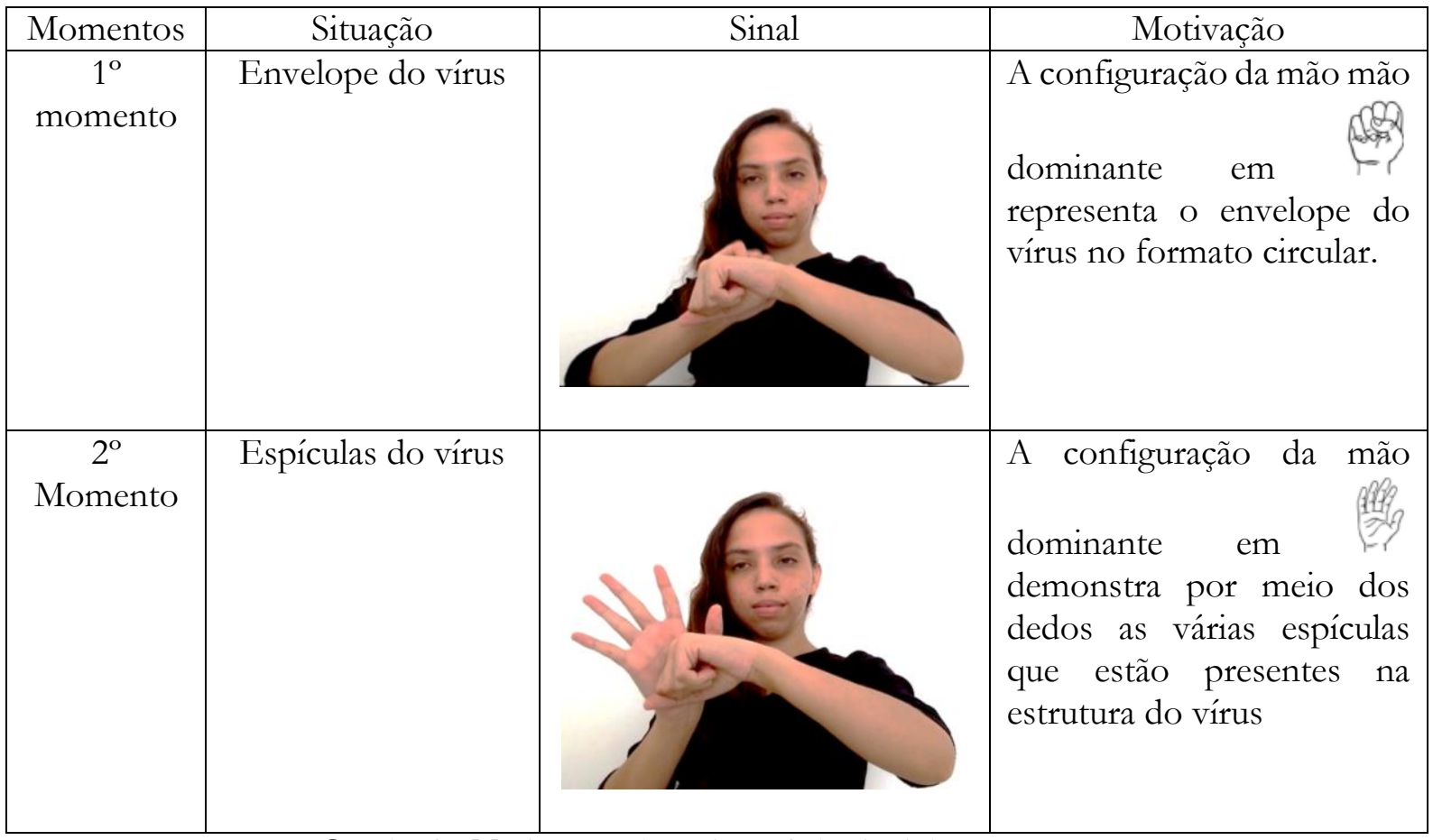

Quadro 2 - Motivações da variante 2 do sinal de coronavírus 
(iii) Variante 3

Fonte: elaborado pelos autores, 2021.

Apesar de já estar em uso no Brasil uma variante do sinal de coronavírus, por meio do empréstimo linguístico do sinal criado pelos orientais, os surdos brasileiros iniciaram uma nova discussão sobre o sinal para designar o vírus/doença. Dessa maneira, eles criaram uma nova variante, que denominamos de variante 3 (figura 8).

Dessa maneira, tanto a variante 2 quanto a variante 3 passaram a ser utilizadas de maneira concomitante em território nacional. Contudo, a variante nacional passou a ser usada com maior frequência pelos brasileiros.


Figura 8 - Variante 3 do sinal de coronavírus Fonte: elaborado pelos autores, 2021.

Em consulta ao vídeo 3 disponibilizado nas redes sociais, em que o surdo explica as motivações para a criação do novo sinal, analisamos de acordo com o modelo de Taub (2004), dois esquemas de iconicidade que podem ser estabelecidos para a criação da variante 3 .

O primeiro esquema, apresentado na figura 9, se aproxima da explicação que demos para o esquema da variante 2. Nesse sentindo, a estrutura do vírus que gera a doença é levada em consideração para sua criação. Portanto, entram para a esquematização o envelope e a espícula presentes na estrutura do vírus. Contudo, há nessa esquematização a demarcação da espícula do vírus por trás e pela frente do envelope.

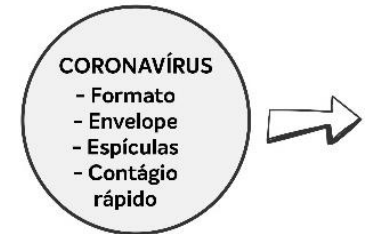

Conceito

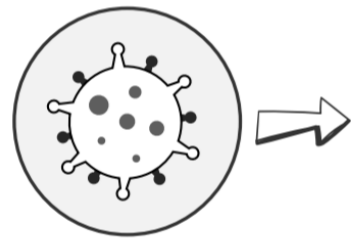

Imagem mental

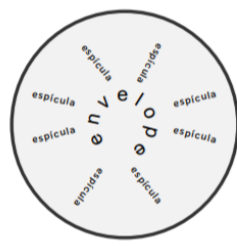

Esquematização

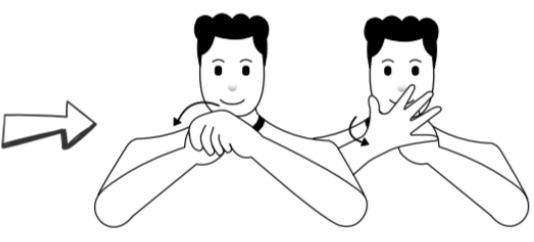

Codificação

Figura 9 - Proposta 1 da variante 3 no modelo de Taub, 2004. Fonte: elaborado pelos autores, 2021.

Outro esquema de iconicidade (figura 10) que estabelecemos para a variante 3 está relacionado aos conceitos de contágio rápido e sintomas da doença. Estabelecemos esse esquema a partir das explicações da criação do sinal apresentada no vídeo de divulgação.

São selecionados para esse sinal a esquematização de pessoas contaminadas e os sintomas causados pela doença. 


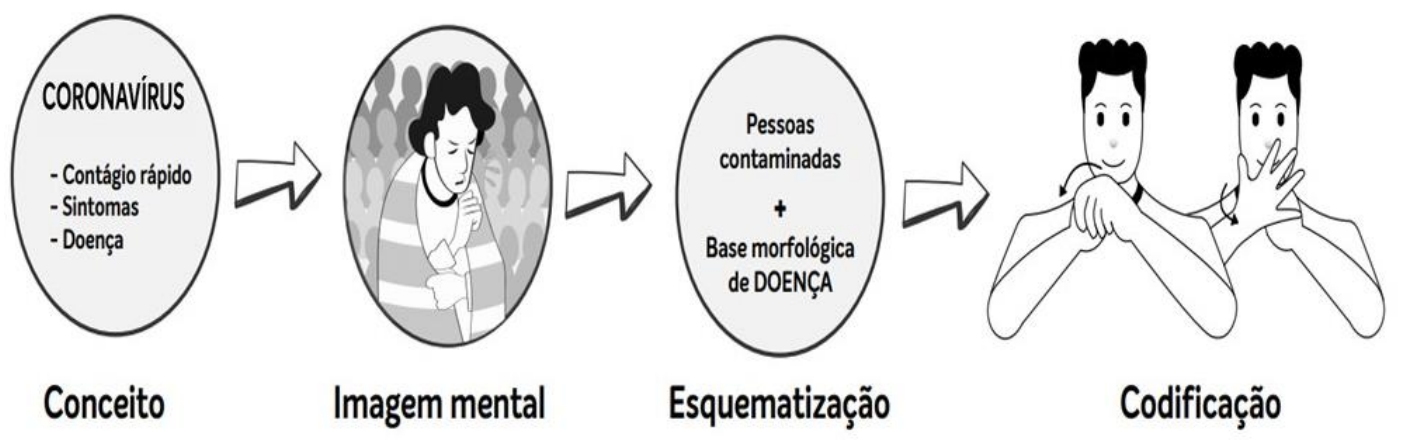

Figura 10 - Proposta 2 da variante 3 no modelo de Taub, 2004. Fonte: elaborado pelos autores, 2020.

Analisamos a constituição paramétrica da variante 3 a partir do segundo esquema de iconicidade, por conta de essa ser a explicação apresentado no vídeo de divulgação do sinal. Descrevemos a constituição paramétrica no quadro 3.

Somente nessa variante percebemos uma base morfológica na constituição do sinal. Uma explicação para esse fato é a de que esse é o único sinal criado pelos surdos brasileiros, sendo os demais empréstimos linguísticos. Dessa maneira, os surdos se valem de recursos linguísticos já presentes na Libras.

\begin{tabular}{|c|c|c|c|}
\hline Momentos & Situação & Sinal & Motivação \\
\hline $\begin{array}{c}1^{\mathrm{o}} \\
\text { momento }\end{array}$ & Doença & & $\begin{array}{l}\text { A configuração da mão não } \\
\text { dominante em é estabelecida a } \\
\text { partir da mesma configuração de } \\
\text { mão do sinal referente à DOENÇA } \\
\text { em Libras. Dessa forma, a } \\
\text { configuração é mantida nesse sinal, } \\
\text { como em outros sinais que são } \\
\text { derivados da base DOENÇA. }\end{array}$ \\
\hline $\begin{array}{c}2^{\circ} \\
\text { momento }\end{array}$ & $\begin{array}{c}\text { Contágio } \\
\text { Rápido }\end{array}$ & & $\begin{array}{l}\text { As duas configurações da mão } \\
\text { dominante demonstram o contágio } \\
\text { rápido do vírus para várias pessoas, } \\
\text { começando de um número } \\
\text { reduzido, representado pela } \\
\text { configuração em dedo estendido e } \\
\text { nenhum dom } \\
\text { passando para um quantitativo } \\
\text { grande de pessoas, representado } \\
\text { pela configuração em } \\
\text { todos os dedos estendidos. }\end{array}$ \\
\hline
\end{tabular}

Quadro 3 - Motivações da variante 3 do sinal de coronavírus

Fonte: elaborado pelos autores, 2021. 
Dessarte, analisamos que a emergência de contextos específicos, como o advento do novo coronavírus em todo o mundo, provoca as línguas a criarem de maneira imediata termos para denominarem esses novos contextos.

Assim, os falantes emergem esses novos sinais e palavras de diversas formas, por meio de empréstimos linguísticos, criação de termos a partir de bases morfológicas pré-existentes nas línguas ou por meio de termos inovadores, nunca utilizados. Na Libras, a partir de nossas análises, percebemos que os empréstimos linguísticos e a criação de sinais a partir de bases morfológicas pré-existentes se destacam na criação dos termos para designar o vírus e a doença.

Além disso, é importante pontuar que a iconicidade analisada a partir do modelo de Taub (2004), as vezes é bem transparente e por vezes não é tão evidente, como demonstrado na variante 2 e no segundo esquema da variante 3 , respectivamente.

\section{CONSIDERAÇÕES FINAIS}

A disseminação da COVID-19 por todo mundo fez com que os falantes das diversas línguas orais e de sinais começassem a pensar nos termos que seriam usados para nomear os conceitos e situações relacionados à doença.

$\mathrm{Na}$ Libras, alguns termos surgiram para designar conceitos como, quarentena, coronavírus, COVID-19, isolamento social, pandemia e etc. Nesta pesquisa, focamos nossa atenção no termo principal desse contexto emergente: coronavírus e COVID-19.

Dessa forma, em nossos dados encontramos três variantes para se referir ao vírus. $\mathrm{O}$ processo de criação desses sinais revela motivações relacionadas à origem da doença, à estrutura do vírus e ao contágio e sintomas da doença.

A estrutura fonológica das variantes revela o importante papel da configuração de mão e do movimento na constituição dos sinais. Esses dois parâmetros se destacam na visualização da iconicidade nos sinais, fazendo referência à situações, estrutura, contágio e sintomas relacionados ao coronavírus.

Nossa análise nos leva a concluir que em léxicos emergentes a iconicidade tem um papel fundamental na constituição dos termos. Ao passar dos anos, caso a temática ainda seja tratada em diversos espaços, podemos ter uma mudança na estrutura desses sinais, como resultado da economia linguística.

Portanto, a iconicidade demonstrada nas variantes desta pesquisa reafirma o papel desse fenômeno nas LS. Uma vez que, esse fator não à rebaixa ao status de língua não natural, mas sim, demonstra uma peculiaridade das línguas sinalizadas, que é a iconicidade. Mostrando assim, a riqueza dessas línguas.

\section{REFERÊNCIAS BIBLIOGRÁFICAS}

ANTUNES, Irandé. Território das palavras: estudo do léxico em sala de aula. São Paulo: Parábola Editorial, 2012.

BRENTARI, D., PADDEN, C. A. Native and Foreign Vocabulary in Sign Language: a Lexicon with Multiple Origins. In: BRENTARI, D. (Ed.), Foreign vocabulary in sign languages: a cross-linguistic investigation of word formation. New Jersey/London: Lawrence Erlbaum Associates, 2001.

GERHARDT, Tatiana Engel; SILVEIRA, Denise Tolfo. Método de Pesquisa. Universidade Federal do Rio Grande do Sul. Porto Alegre: Editora da UFRGS, 2009. 
GIL, Antônio Carlos. Métodos e técnicas de pesquisa social. Antônio Carlos Gil. - 6. ed. - São Paulo: Atlas, 2008.

NAVES, T.; MINEIRO, A.; MORGADO, C. Analysis of the iconicity of four proposals of neological denominations for Physics (acoustic) concepts in BSL. SENSOS-e, v. VI, n. 1, p. 104128, 2019. Disponível em: https://parc.ipp.pt/index.php/sensos/article/view/3461.

QUADROS, R. M. de. Libras - Linguística para o ensino superior 5. $1^{\mathrm{a}}$ ed. São Paulo: Parábola Editorial, 2019.

QUADROS, R. M. de, KARNOPP, L. Língua de Sinais Brasileira - Estudos Linguísticos. Porto Alegre: Artmed, 2004.

TAUB, S. F. Language from the body: Iconicity and Metaphor in American Sign Language. 1. ed. Cambridge: Cambridge University Press, 2004.

TAUB, S. F. OMASON, R. L. Iconicity and metaphor in sign languages: recente studies. Tic Talk - UBS Translation Information Clearinghouse Newsletter. N 55, 2003.

Submetido em 04/02/2020

Aceito em 17/03/2021 